\title{
ASSESSMENT OF SEXUAL FUNCTION IN PATIENTS UNDERGOING VASECTOMY USING THE INTERNATIONAL INDEX OF ERECTILE FUNCTION
}

\author{
EDUARDO BERTERO, JORGE HALLAK, CELSO GROMATZKY, ANTONIO M. LUCON, \\ SAMI ARAP
}

General Hospital, School of Medicine, University of Sao Paulo, USP, Sao Paulo, SP, Brazil

\begin{abstract}
Introduction: The present study aims to prospectively compare the sexual function in males before and after vasectomy surgery using the international index of erectile function (IIEF).

Materials and Methods: From October to December 2002, sixty-four patients who were candidates for male sterilization in the vasectomy program of the Urology Section at the General Hospital of the University of São Paulo were included. The same investigator applied the IIEF before and 90 days after the surgery. The mean scores obtained on pre and postoperative visits for all domains of sexual function were analyzed and compared with the Wilcoxon test.

Results: The mean patient age was 35 years (range from 25 to 48 years) and the mean number of children per man was 3 . The total mean score of the IIEF was 64.06 before surgery and 65.64 after the procedure, with this difference considered statistically significant $(\mathrm{p}<0.001)$. Sixty-seven per cent of the patients improved their scores, versus $17 \%$ and $16 \%$ who showed worsening or no change at all in IIEF scores following surgery, respectively. Of the 5 sexual function domains, desire and sexual satisfaction presented statistically significant improvement.

Conclusion: This study showed that vasectomy caused a positive impact on sexual function, especially on desire and sexual satisfaction, in the majority of men undergoing surgery. There was no case of surgery-related erectile dysfunction.
\end{abstract}

Key words: vasectomy; sexual activity; questionnaires; IIEF

Int Braz J Urol. 2005; 31: 452-8

\section{INTRODUCTION}

Currently, voluntary male sterilization through vasectomy is a very common procedure, which presents low complication rates (1-4). Postvasectomy sexual dysfunction has been reported in the literature and is defined as a psychological complication of the surgery (5-7). Though many papers have reported post-vasectomy complications, only a few deal with psychological or sexual issues $(7,8)$. In general, the incidence of psychological or sexual prob- lems following vasectomy has been reported at between 1 and 3\% (8). However, none of these studies used the international index of erectile function (IIEF) for assessing post-vasectomy erectile function.

The IIEF is a questionnaire developed in 1997, for assessing the efficacy of sildenafil in patients treated for erectile dysfunction (9). Since then, it has been used as the gold-standard tool for assessing efficacy in results from several clinical trials regardless of the type of treatment or population under study. Recently, an extensive review of IIEF applica- 
tion in several subpopulations was published, although it did not include vasectomized patients (10). The questionnaire consisted of 15 items that should be answered by the patient himself with no interference from third parties. In 1999, through the "First Consultation on Erectile Dysfunction," the World Health Organization adopted the IIEF as the main tool for assessing efficacy in clinical studies (11). The IIEF has been already validated in 32 languages, including Portuguese (12).

The object of this study is to prospectively assess through the IIEF the change in sexual function following voluntary vasectomy.

\section{MATERIALS AND METHODS}

We selected 65 patients from October to December 2002 who had appointments scheduled for the vasectomy program of the Urology Section at the General Hospital of the University of São Paulo. Ages ranged from 25 to 48 years $(35 \pm 6)$.

On average, patients had 3 living children $( \pm$ 1) ranging from 1 to 6 years of age. The mean age of the youngest child was 18 months ( \pm 20 months), ranging from 4 months to 12 years (Figure-1).

This study was approved by the Institutional Medical Ethics Committee, and all couples signed the informed consent form in order to participate in the research. On the day of the first interview, both the patient and his partner signed the responsibility form in accordance with Law 9.263 from January 12, 1996 regarding the regulation of family planning (13).

We included patients who were candidates for vasectomy who were in accordance with the aforementioned law, and who complied with the following requirements: 1) two living children or, 2) older than 25 years. Additionally, the aforementioned law states that a minimum period of 60 days should be observed between the manifestation of will and the surgical act. During this period, the interested individual will be provided with access to a fertility regulation service, including counseling by a multidisciplinary team aiming to discourage early sterilization $(13,14)$. All couples that were interviewed and participated in this study have respected this period. One patient was excluded because he had abstained from sexual intercourse during the 4 weeks preceding the application of the questionnaire at the first interview. Therefore, the study group was composed of 64 men.

The study design involved applying the IIEF with 15 questions (IIEF-15) on a first occasion before surgery, which was called visit 1 , and then a second time, called visit 2, on average 93 days follow-

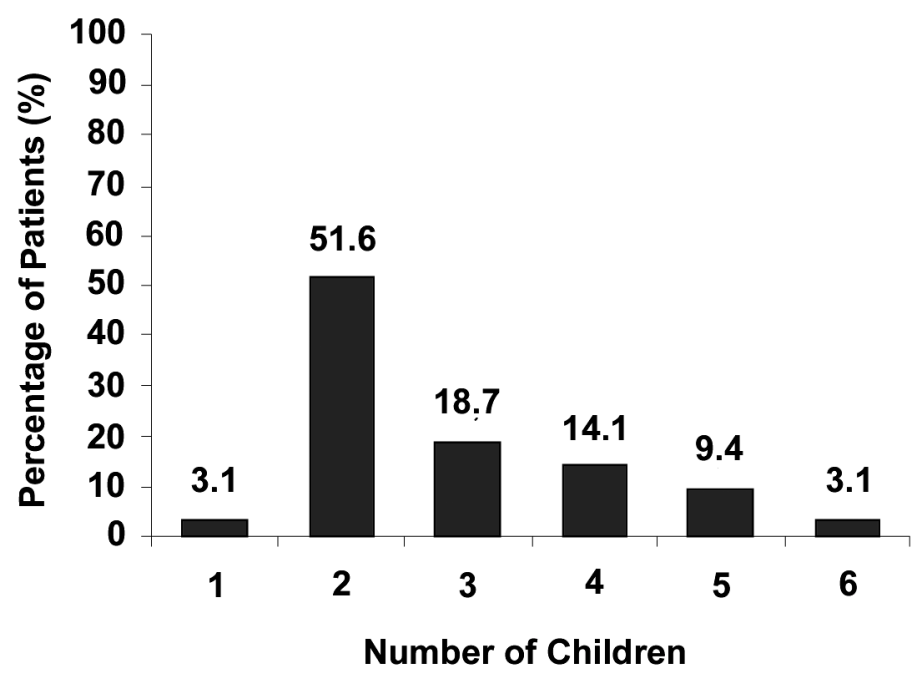

Figure 1 - Number of children per vasectomized patient. 
ing vasectomy (70 to 126 days). Patients completed the questionnaire during visit 1 on the same day that the social worker conducted the interview and requested the signature of the informed consent and responsibility term. Thus, the patients would have to comply with the 60-day period and would be able to discuss with their partners other commercially available contraceptive methods. The same physician (EB) always performed both visits.

The IIEF-15 was fully applied to the patient according to the Portuguese-validated version (12). The questions are divided into 5 sexual function domains: erectile function (questions 1 to 5 and 15), sexual satisfaction (questions 6, 7 and 8), orgasm (questions 9 and 10), sexual desire (questions 11 and 12) and overall satisfaction (questions 13 and 14). Each question has a value ranging numerically from 0 to 5 , with the lowest value presenting the poorer sexual response. Therefore, the total possible score is 75 . The total score of items relative to erectile function as adopted by the "1st International Consultation on Erectile Dysfunction" are questions 1 to 5 and 15 (11). Based on this score, the degree of erectile dysfunction is defined as normal (> 25), mild (21 to 24 ), moderate (16 to 20 ) and severe $(<15)$.

On visit 2, the IIEF-15 was applied again in the same way as on visit 1 . This follow-up visit was performed on the seventh postoperative day by the same physician that performed the surgery. Also on visit 2, the patient was given the results of the seminal analysis, which had been performed approximately 60 days following the vasectomy.

The vasectomy procedure was performed at the hospital's outpatient clinic using the traditional technique.

The quantitative variables were represented by mean and standard deviation, and qualitative variables were absolute and relative frequency. Non-parametric tests were used due to the nature of quantitative data; discrete continuous variables. Comparison between assessments on visits 1 and 2 in relation to the scores obtained on isolate questions, the sum of questions in each domain, and the total score, was performed by the Wilcoxon test for related samples. A significance level of $p<0.05$ was adopted.

\section{RESULTS}

In relation to the 5 sexual function domains, statistically significant variations were found for the domains of sexual desire and sexual satisfaction ( $\mathrm{p}=$ 0.05 and $\mathrm{p}=0.003$, respectively), with the score on visit 2 being significantly higher than on visit 1 (Tables-1 and 2).

Table 1 - Score and questions related to the sexual desire domain of the IIEF on visits 1 and $2(n=64)$.

\begin{tabular}{lccc}
\hline IIEF - Sexual Desire Domain & $\begin{array}{c}\text { Visit 1 } \\
\text { Mean } \pm \text { SD }\end{array}$ & $\begin{array}{c}\text { Visit 2 } \\
\text { Mean } \pm \text { SD }\end{array}$ & $\begin{array}{c}\text { P value } \\
\text { (Wilcoxon test) }\end{array}$ \\
\hline Score & $7.75 \pm 1.40$ & $8.25 \pm 1.11$ & $0.005 *$ \\
Question 11 & $4.16 \pm 0.93$ & $4.36 \pm 0.70$ & 0.082 \\
Question 12 & $3.59 \pm 0.77$ & $3.89 \pm 0.76$ & $0.001 *$ \\
\hline
\end{tabular}

Table 2 - Score and questions related to the sexual satisfaction domain of the IIEF on visits 1 and $2(n=64)$.

\begin{tabular}{lccc}
\hline IIEF - Sexual Satisfaction Domain & $\begin{array}{c}\text { Visit 1 } \\
\text { Mean } \pm \text { SD }\end{array}$ & $\begin{array}{c}\text { Visit 2 } \\
\text { Mean } \pm \text { SD }\end{array}$ & $\begin{array}{c}\text { P value } \\
\text { (Wilcoxon test) }\end{array}$ \\
\hline Score & $11.59 \pm 2.27$ & $12.16 \pm 2.08$ & $0.003 *$ \\
Question 6 & $3.14 \pm 1.40$ & $3.61 \pm 1.00$ & $0.002 *$ \\
Question 7 & $4.47 \pm 0.94$ & $4.50 \pm 0.80$ & 0.586 \\
Question 8 & $3.98 \pm 0.75$ & $4.05 \pm 0.81$ & 0.413 \\
\hline
\end{tabular}


Concerning the erectile function domain, we did not observe in any of the 64 studied patients a postoperative sum lower than 26 , thus indicating that there was no case of erectile dysfunction related to vasectomy surgery in this study (Table-3).

No statistically significant variation was found for scores in the domains of orgasm and overall satisfaction between the visits, though an increase in the score sum was identified on visit 2 (Tables- 4 and 5).

Table- 6 presents the results for mean score of the total score IIEF- 15 between visits 1 and 2 where a statistically significant variation was found between visits ( $p<0.001$ ), with the score on visit 2 being significantly higher than on visit 1 .

Figure- 2 shows the distribution of the 64 patients relative to the comparison between total scores on visits 1 and 2 .

\section{COMMENTS}

Voluntary male sterilization or vasectomy has become the best contraceptive method performed on males, primarily because of its simplicity, effectiveness, and low complication rates (15). Approximately 100 million men have already been vasectomized

Table 3 - Score and questions related to the erectile function domain of the IIEF on visits 1 and $2(n=64)$.

\begin{tabular}{lrrc}
\hline IIEF - Erectile Function Domain & \multicolumn{1}{c}{$\begin{array}{c}\text { Visit 1 } \\
\text { Mean } \pm \text { SD }\end{array}$} & $\begin{array}{c}\text { Visit 2 } \\
\text { Mean } \pm \text { SD }\end{array}$ & $\begin{array}{c}\text { P value } \\
\text { (Wilcoxon test) }\end{array}$ \\
\hline Score & $26.80 \pm 3.41$ & $27.05 \pm 3.50$ & 0.212 \\
Question 1 & $4.61 \pm 0.81$ & $4.53 \pm 0.84$ & 0.791 \\
Question 2 & $4.63 \pm 0.72$ & $4.55 \pm 0.82$ & 0.748 \\
Question 3 & $4.63 \pm 0.70$ & $4.58 \pm 0.77$ & 1.000 \\
Question 4 & $4.34 \pm 0.95$ & $4.58 \pm 0.81$ & $0.034 *$ \\
Question 5 & $4.75 \pm 0.85$ & $4.81 \pm 0.71$ & 0.683 \\
Question 15 & $3.84 \pm 0.80$ & $4.00 \pm 0.76$ & $0.019 *$ \\
\hline
\end{tabular}

Table 4 - Score and questions related to the orgasm domain of the IIEF on visits 1 and $2(n=64)$.

\begin{tabular}{lccc}
\hline IIEF - Orgasm Domain & $\begin{array}{c}\text { Visit 1 } \\
\text { Mean } \pm \text { SD }\end{array}$ & $\begin{array}{c}\text { Visit 2 } \\
\text { Mean } \pm \text { SD }\end{array}$ & $\begin{array}{c}\text { P value } \\
\text { (Wilcoxon test) }\end{array}$ \\
\hline Score & $9.03 \pm 1.45$ & $9.19 \pm 1.51$ & 0.136 \\
Question 9 & $4.67 \pm 0.62$ & $4.66 \pm 0.76$ & 0.874 \\
Question 10 & $4.36 \pm 1.12$ & $4.53 \pm 0.87$ & 0.128 \\
\hline
\end{tabular}

Table 5 - Score and questions related to the overall satisfaction domain of the IIEF on visits 1 and $2(n=64)$.

\begin{tabular}{lccc}
\hline IIEF - Overall Satisfaction Domain & $\begin{array}{c}\text { Visit 1 } \\
\text { Mean } \pm \text { SD }\end{array}$ & $\begin{array}{c}\text { Visit 2 } \\
\text { Mean } \pm \text { SD }\end{array}$ & $\begin{array}{c}\text { P value } \\
\text { (Wilcoxon test) }\end{array}$ \\
\hline Score & $8.89 \pm 1.43$ & $9.00 \pm 1.40$ & 0.268 \\
Question 13 & $4.39 \pm 0.75$ & $4.48 \pm 0.73$ & 0.289 \\
Question 14 & $4.50 \pm 0.78$ & $4.52 \pm 0.76$ & 0.855 \\
\hline
\end{tabular}


Table 6 - Total score of the IIEF applied on visits 1 and $2(n=64)$.

\begin{tabular}{lccc}
\hline IIEF - 15 & $\begin{array}{c}\text { Visit 1 } \\
\text { Mean } \pm \text { SD }\end{array}$ & $\begin{array}{c}\text { Visit 2 } \\
\text { Mean } \pm \text { SD }\end{array}$ & $\begin{array}{c}\text { P value } \\
\text { (Wilcoxon test) }\end{array}$ \\
\hline Total Score & $64.06 \pm 7.49$ & $65.64 \pm 7.89$ & $<0.001 *$ \\
\hline
\end{tabular}

worldwide as a method of family planning (16). One great concern for men who choose this sterilization method has always been the capacity of maintaining a satisfactory sexual life following surgery (7).

Erectile dysfunction is considered to be a serious psychological complication following a vasectomy surgery (7). Though the procedure has been proven not to cause any damage to erection or ejaculation mechanisms, $0.3 \%$ of patients operated in one study have complained of erectile dysfunction (1). According to this same author, in one study with 1000 men undergoing vasectomy who were given questionnaires, the results were as follows: $99 \%$ of the men and $95 \%$ of their wives were happy with the surgical result; concerning their sexual life, $60 \%$ stated that it was better, $2.5 \%$ worse and $37 \%$ reported that their sexual performance had not changed at all.

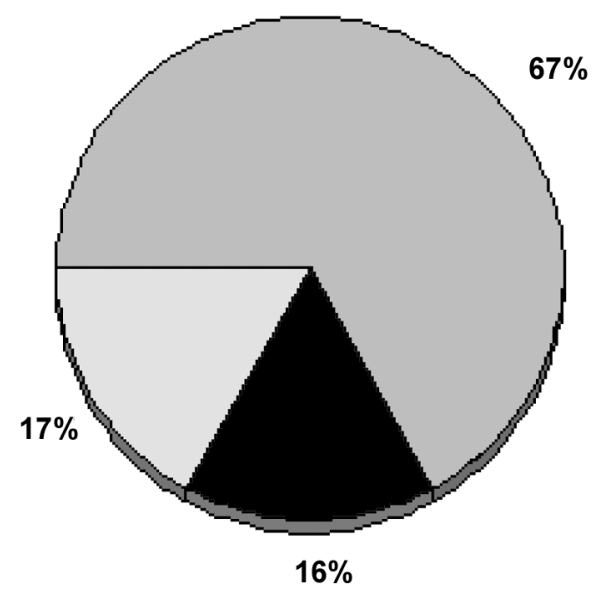

In one of the largest series published on vasectomy performed by the same surgeon totaling 6248 cases, post-vasectomy sexual dysfunction was reported by 39 men (4). In this paper, no specific validated tool or questionnaire was used to identify sexual or erectile dysfunction, which could certainly lead to an inaccurate number of men with this complaint.

Contrarily, in other publications the psychological effects of vasectomy are uniformly positive, improving sexual intercourse, harmony between the couple, libido and increasing sexual frequency (1719). One exception for the series of positive results is the anecdotal and curious case published in 1980 where a man reported having changed his sexual preference and becoming homosexual as a direct consequence of the surgery (20).

Figure 2 - Comparison between total scores on the IIEF applied on visits 1 and $2(n=64)$. 
In this study, the first one using the IIEF-15 as a tool for assessing sexual changes following vasectomy, the mean total score before and after vasectomy was 64.06 and 65.64 respectively, out of a total of 75 points. This difference, which is favorable to vasectomy, was statistically significant. This data is strongly representative and means an overall improvement in sexual function following surgery.

When considering the IIEF in the domain of erectile function (questions 1 to 5 and 15), the mean score before and after surgery was 26.80 and 27.05 , respectively. Though the difference was not statistically significant, it shows that the vasectomy did not have any psychologically negative impact that could contribute to the development of erectile dysfunction, as other studies have stressed.

Performance anxiety can be caused by several factors, such as stress and fear, which culminate in a discharge of the neurohormones, adrenaline and noradrenaline, with consequent contraction in the cavernous smooth muscles and resulting detumescence and, thus, inability to maintain an erection long enough to complete sexual intercourse. Question 4 of the IIEF related to the ability to maintain an erect penis inside the partner following penetration. In this study, this item had a statistically higher score on visit 2 , thus suggesting that men feel more secure and selfassured during coitus following surgery.

Additionally, in relation to self-assurance, when we analyze the statistical differences in the mean scores between visits for question 15 , which refers to the self-assurance of men in obtaining and maintaining an erection, we stress the theory that following vasectomy surgery male self-assurance can be increased during coitus. We believe that male self-assurance increases as a consequence of his unconcern with pregnancy following sterilization. When considering question 6 of the IIEF, which refers to sexual frequency during the past 4 weeks, the mean score on the pre-vasectomy visit was 3.14 , which means sexual intercourse 5 to 6 times per month. Following surgery there was an increase in sexual frequency represented by the increase in the score for this item to 3.61 , which was statistically significant. This data suggests that patients have a greater frequency of sexual intercourse after under- going sterilization, mainly because they do not have to worry anymore about family planning or an unwanted pregnancy.

Other relevant data taken from this study was the finding that $67 \%$ of patients under study have improved their total of IIEF items when comparing visits 1 and 2, which means a slight tendency towards an improvement in sexual function following vasectomy surgery. On the other hand, only $17 \%$ of operated men have decreased their IIEF totals 90 days following surgery. It is worth stressing that even if these patients have lower IEFF totals following surgery, no case was considered as clinically significant. In other words, based on the IIEF no patient was categorized as having ED following surgery.

Among the patients whose mean score had worsened following vasectomy, we identified a statistically significant difference in questions 1,2 and 8 of the IIEF. Questions 1 and 2 refer to erectile function itself. Question 8 concerns sexual satisfaction. Though no case of ED has been diagnosed using the IIEF criteria in this group of patients $(n=$ 11), we attribute this decrease in score to several reasons, including anxiety and expectation generated for the waiting time until the sperm analysis result, use of condoms until being certain of having achieved azoospermia and fear of pain during ejaculation.

An interesting finding was the significant improvement seen in the domains of desire and sexual satisfaction, when comparing pre and postoperative visits, once again confirming the influence and positive impact that vasectomy can have on the sexual life of these men. When considering other sexual function domains, such as orgasm and overall satisfaction, there was no significant difference between the score from the previous visit and that obtained 90 days following vasectomy.

\section{CONCLUSION}

We observed an improvement in sexual function, especially in the domains of desire and sexual satisfaction, in this group of patients undergoing vasectomy. There was no case of surgery-related erectile dysfunction. 


\section{REFERENCES}

1. Finkbeiner AE, Bissada NK, Redman JF: Complications of vasectomies. Am Fam Physician. 1977; 15: 86-9.

2. Gingell C, Crosby D, Carroll R: Review of the complications and medicolegal implications of vasectomy. Postgrad Med J. 2001; 77: 656-9.

3. Hendrix NW, Chauhan SP, Morrison JC: Sterilization and its consequences. Obstet Gynecol Surv. 1999; 54: 766-77.

4. Schmidt SS: Vasectomy by section, luminal fulguration and fascial interposition: results from 6248 cases. Br J Urol. 1995; 76: 373-4; discussion 375.

5. Garrison PL, Gamble CJ: Sexual effects of vasectomy. J Am Med Assoc. 1950; 144: 293-5.

6. Dias PL: The long-term effects of vasectomy on sexual behaviour. Acta Psychiatr Scand. 1983; 67: 333-8.

7. Buchholz NP, Weuste R, Mattarelli G, Woessmer B, Langewitz W: Post-vasectomy erectile dysfunction. J Psychosom Res. 1994; 38: 759-62.

8. Jones E: Vasectomy sequelae: empirical studies. J Reprod Med. 1977; 19: 254-8.

9. Rosen RC, Riley A, Wagner G, Osterloh IH, Kirkpatrick J, Mishra A: The international index of erectile function (IIEF): a multidimensional scale for assessment of erectile dysfunction. Urology. 1997; 49: 822-30.

10. Rosen RC, Cappelleri JC, Gendrano N 3rd: The International Index of Erectile Function (IIEF): a state- of-the-science review. Int J Impot Res. 2002; 14: 22644.

11. Jardin A, Wagner G, Khoury S, Giuliano F, PadmaNathan H, Rosen R: Erectile Dysfunction: $1^{\text {st Interna- }}$ tional Consultation on Erectile Dysfunction. Health Publications, Plymouth, UK. 2000.

12. Ferraz MB, Ciconelli M Jr: Translation and cultural adjustment of the international index of erectile function to Portuguese. Rev Bras Med. 1998; (special edition). [in Portuguese]

13. Federal Constitution: Law \#9263. 1996; Chap. I, art. 10. [in Portuguese]

14. Ferriani RA: The sterilization law. Reprod Clim. 1997; 12: 161-2. [in Portuguese]

15. Haldar N, Cranston D, Turner E, MacKenzie I, Guillebaud J: How reliable is a vasectomy? Long-term follow-up of vasectomised men. Lancet. 2000; 356: 43-4.

16. Weiske WH: Vasectomy. Andrologia. 2001; 33: 125-34.

17. Frances M, Kovacs GT: A comprehensive review of the sequelae of male sterilization. Contraception. 1983; 28: 455-73.

18. Leavesley JH: A study of vasectomized men and their wives. Aust Fam Physician. 1980; 9: 8-10.

19. Maschhoff TA, Fanshier WE, Hansen DJ: Vasectomy: its effect upon marital stability. J Sex Res. 1976; 12: 295-314.

20. Bass C, Rees D: Homosexual behaviour after vasectomy. Br Med J. 1980; 281: 1460.

Received: April 14, 2005 Accepted after revision: June 10, 2005

\section{Correspondence address:}

Dr. Eduardo Bertero

Rua Vieira de Moraes, 420 / 87

São Paulo, SP, 04617-000, Brazil

Fax: + $55115542-9557$

E-mail: urologia-sp@uol.com.br 